140

VALUTAZIONE DI UN NUOVO KIT MOLECOLARE PER LA DIAGNOSI RAPIDA DELLE BATTERIEMIE

\author{
Matti C., Daturi R., Sacco L., Giacobone E. \\ Fondaz. I.R.C.C.S. Policlinico 'San Matteo', V. le Golgi, 2, \\ 27100 Pavia
}

Introduzione. La batteriemia rimane una causa importante di morbidità e mortalità, specialmente in pazienti immunocompromessi. Attualmente, presunte batteriemie sono trattate in modo empirico con antibiotici a largo spettro, in quanto una diagnosi definitiva è resa possibile solo dalle emocolture, che richiedono tempi prolungati nell'identificazione. In questo studio preliminare si vogliono confrontare i risultati ottenuti mediante un nuovo saggio molecolare (GenoType BC Gram positive ${ }^{\circledR}$-Hain Lifescience) per la rapida identificazione dei piu'importanti batteri coinvolti nelle batteriemie con lo strumento automatico Phoenix (BD) per identificazione ed antibiogramma.

Metodi. 42 emocolture positive al BACTEC (BD) sono state caratterizzate con la colorazione di Gram ed in seguito identificate fenotipicamente con il sistema Phoenix (BD).

Per l'identificazione molecolare, 20ul di emocoltura positiva sono spottati su una matrice per l'estrazione del DNA (GenoCard ${ }^{\circledast}$, Hain Lifescience), dalla quale con una penna perforatrice si preleva un tassello di $1 \mathrm{~mm}$ di diametro e di seguito si aggiunge alla mix di amplificazione. L'amplificazione e l'ibridazione inversa su strip è condotta seguendo il protocollo del kit GenoType BC Grampositive ${ }^{\circledR}$.

Risultati. GenoType BC Grampositive ${ }^{\circledR}$ ha identificato circa il 96\% delle specie batteriche e il 100\% dei geni di resistenza: solo in due casi non è stata possibile l'identificazione, in quanto assenti le sonde specifiche sulla strip.

Conclusioni. Il saggio molecolare GenoType BC Grampositive $^{\circledast}$ ha dimostrato di riconoscere con estrema precisione i piu'importanti batteri causa di sepsi e i geni associati alla resistenza agli antibiotici. Si è inoltre rivelato di semplice utilizzo con risultati disponibili in poco più di quattro ore . Il kit GenoType BC si è rivelato molto utile nella diagnosi rapida delle sepsi con indiscusso vantaggio per i pazienti immunocompromessi.

\section{1 \\ DIAGNOSI MOLECOLARE DI M.Tubercolosis.: “Amplified MTD”, MULTIPLEX-PCR* E REAL-TIME* PCR (*home-made) A CONFRONTO}

Morelli S., Pace A., Fantini S., Torsani M, Sambri V., Nanetti A., Dal Monte P.

DMCSS, sez. Microbiologia, Università di Bologna, via Massarenti 9, 40138 Bologna

Introduzione. I lunghi tempi necessari alla crescita in coltura di $M$. Tuberculosis, spingono sempre più ad affinare tecniche molecolari in grado di dare un risultato specifico in tempi rapidi.

Metodi. Da diversi anni impieghiamo il sistema "Amplified MTD" che impiega il metodo TMA (Transcription-Mediated-Amplification) per identificare in maniera qualitativa l'rRNA di $M$. tuberculosis complex nei materiali respiratori. Questo metodo presenta almeno due grossi limiti: è piuttosto indaginoso e ci sembra difficoltosa la gestione dei dati negativi: il campione è un vero negativo, oppure l'infezione è dovuta ad un micobatterio non tubercolare (MNT). Abbiamo quindi messo a punto una multiplex- PCR che utilizza due coppie di primers: ITS-F e Mycom-2 che amplificano un frammento di 300 bps specifico per Mycobacterium spp., e TBF e TBR che amplificano una regione specifica di $M$. tuberculosis di $121 \mathrm{bps}$ (Heekyung et al. J. Clin. Microb., 2000; 38:4080-4085). Con le due tecniche sono stati saggiati 75 campioni provenienti dalle vie respiratorie. Per gli stessi sono stati rispettivamente allestite le colture standard. Inoltre per 10 ceppi noti, (1 Stafilococco spp., 1 Streptococco fecalis, 1 Escherichia coli, $1 \mathrm{C}$. albicans, $4 \mathrm{M}$. tuberculosis, $1 \mathrm{M}$. avium, $1 \mathrm{M}$. gordonae) è stata tentata un Real-time PCR utilizzando sugli stessi primers la tecnologia CYBR-green. Risultati. La concordanza fra coltura e multiplex è risultata del 93,3\%; fra coltura e “ Amplified MTD” del 89,3\%. Di 16 campioni positivi, la PCR home-made ne ha identificati 11, “Amplified MTD” solo 8. Per quanto riguarda la Real-time PCR questi soni i dati preliminari: solo i ceppi di micobatteri si sono amplificati con i primers per la regione ITS (Tm $88.5^{\circ} \mathrm{C}-89.5^{\circ} \mathrm{C}$ ), e solo i $4 \mathrm{M}$. tuberculosis si sono amplificati con i primers specifici TBR-TBF (Tm $\left.86^{\circ} \mathrm{C}-87^{\circ} \mathrm{C}\right)$.

Conclusioni. La multiplex-PCR ci sembra più completa riuscendo a evidenziare anche le infezioni da MNT grazie ai primers ITS specifici, e con la messa a punto in RealTime si ridurrebbero ulteriormente i tempi diagnostici. 